\title{
The Lowest Deposition of Hg Content is in the Jiaozhou Bay Center
}

\author{
Dongfang Yang ${ }^{1,2, \text { a }}$, TaoJiang ${ }^{1}$, LinzhenWei ${ }^{1}$,Shengjun Zhang ${ }^{1}$,Xinmin Huang ${ }^{1}$ \\ ${ }^{1}$ School of International Economics, Shaanxi Institute of International Trade \& commerce, Xi'an 712046, China; \\ ${ }^{2}$ North China Sea Environmental Monitoring Center, SOA, Qingdao 266033, China;
}

\begin{abstract}
Based on the investigation data of Jiaozhou Bay in 1992, this thesis studied the present situation and horizontal distribution of $\mathrm{Hg}$ content in the bottom of Jiaozhou Bay mouth. The results showed that in May, August and October, the range of $\mathrm{Hg}$ content in the bottom ofJiaozhou Bay was $0.007-0.040 \mu \mathrm{g} / \mathrm{L}$, which was in line with the national water quality standard for class I seawater. This showed that in terms of Hg content, the bottom water of Jiaozhou Bay from the center of the bay to the south of the bay mouth was not polluted by any $\mathrm{Hg}$ content in May, August and October. In the bottom of Jiaozhou Bay, in May, the range of $\mathrm{Hg}$ content in Jiaozhou Bay was $0.013-0.019 \mu \mathrm{g} / \mathrm{L}$. In August, the range of $\mathrm{Hg}$ content in Jiaozhou Bay was $0.021-0.025 \mu \mathrm{g} / \mathrm{L}$. In October, the range of $\mathrm{Hg}$ content in Jiaozhou Bay was $0.007-0.040 \mu \mathrm{g} / \mathrm{L}$. Therefore, in May, August and October, the water of Jiaozhou Bay was not polluted by any $\mathrm{Hg}$ content. In May, a high sedimentation of $\mathrm{Hg}$ contentwas in the coastal waters of the eastern part of the Bay. In August, a high sedimentationof $\mathrm{Hg}$ content was in the coastal waters and the estuary waters in the east of the Bay. In October, a high sedimentation of $\mathrm{Hg}$ content was in the south of the bay mouth. However, from May to August, and then to October, the lowest $\mathrm{Hg}$ content sedimentationwas in the central waters of the Bay.
\end{abstract}

\section{Introduction}

With the increase of human mercury (Hg)emission, the $\mathrm{Hg}$ content is constantly migrating on land, in the atmosphere and in the ocean, and finally reaches the ocean [1-11]. It is not easy for $\mathrm{Hg}$ content to metabolize and degrade from the surface of the ocean to the bottom. Through the effect of vertical water [12-14], the $\mathrm{Hg}$ content changes in the bottom layer of the ocean. Therefore, based on the investigation data of mercury content in Jiaozhou Bay in 1992, this paper studies the bottom layer of Jiaozhou Bay, determines the size, distribution and deposition area of $\mathrm{Hg}$ content, shows the current situation and distribution features of $\mathrm{Hg}$ content in the bottom layer of Jiaozhou Bay, and provides a scientific basis for the study of the existence and migration of $\mathrm{Hg}$ content in the bottom layer.

\section{Investigation Waters, Materials and Methods}

\subsection{Natural Environments of Jiaozhou Bay}

Jiaozhou Bay is located in the south of Shandong Peninsula. Its geographical location is $120^{\circ} 04^{\prime}-120^{\circ}$ $23^{\prime} \mathrm{E}, 35^{\circ} 58^{\prime}-36^{\circ} 18^{\prime} \mathrm{N}$. It is bounded by the line between Tuan island and Xuejia island and connected with the Yellow Sea, covering an area of about 446km2, with an average water depth of about $7 \mathrm{~m}$. It is a typical semi closed Bay. There are more than ten rivers flowing into the sea in Jiaozhou Bay, among which Dagu River, Yang River and Haibo River, Licun River and Loushan River are the ones with large runoff and sediment concentration. These are all seasonal rivers. The hydrological characteristics of these rivers can alter in different seasons $[15,16]$.

\subsection{Materials and Methods}

The survey data of Hg in Jiaozhou Bay in May, August and October 1992 were provided by the North Sea Monitoring Center of The State Oceanic Administration. 5 stations were set up in JiaozhouBay to take water samples: 52, 53, 54, 55, 60 stations (Figure 1). The samples were taken in May, August and October of 1992 respectively. According to the water depth, water samples were taken $(>10 \mathrm{~m}$, surface layer and bottom layer, and $<$ $10 \mathrm{~m}$, only surface layer). The Hg content of Jiaozhou Bay water body was investigated according to the national standard method, which was included in theNational Marine Monitoring Code (1991) [17].

adfyang_dfyang@126.com 


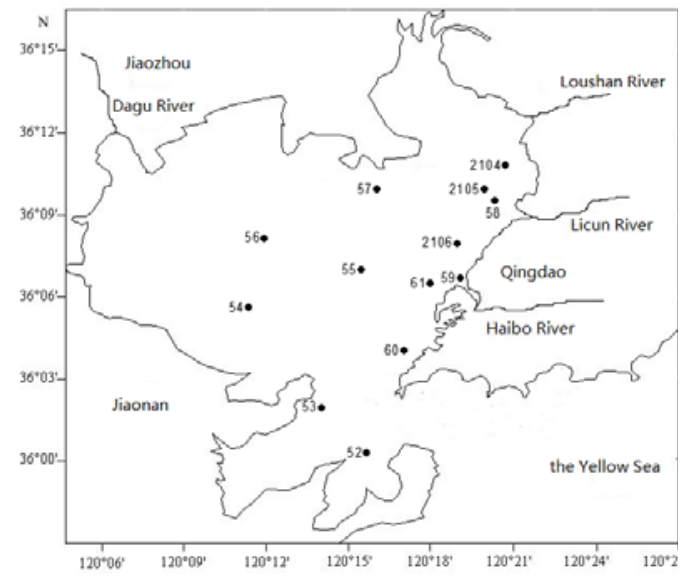

Fig.1 Investigation sites in Jiaozhou Bay

\section{Results}

\subsection{Content in Bottom Layer}

In May, August and October, from the center of Jiaozhou Bay to the south of the bay mouth, the range of $\mathrm{Hg}$ content in the bottom was $0.007-0.040 \mu \mathrm{g} / \mathrm{L}$, which conformed to the national water quality standard for class I seawater $(0.05 \mu \mathrm{g} / \mathrm{L})$. In May, the range of $\mathrm{Hg}$ content in Jiaozhou Bay waters was $0.013-0.019 \mu \mathrm{g} / \mathrm{L}$, which was in line with the national water quality standard for class I seawater. In August, the range of $\mathrm{Hg}$ content in Jiaozhou Bay waters was $0.021-0.025 \mu \mathrm{g} / \mathrm{L}$, which was in line with the national water quality standard for class I seawater. In October, the range of $\mathrm{Hg}$ content in Jiaozhou Bay waters was 0.007$0.040 \mu \mathrm{g} / \mathrm{L}$, which was in line with the national water quality standard for class I seawater. Therefore, in May, August and October, the range of $\mathrm{Hg}$ content in Jiaozhou Bay was $0.007-0.040 \mu \mathrm{g} / \mathrm{L}$, which was in line with the national standard for class I sea water quality. This showed that in terms of $\mathrm{Hg}$ content, in May, August and October, the water in the bottom layer of Jiaozhou Bay, from the center of the bay to the the south of the bay mouth was not polluted by any $\mathrm{Hg}$ content (Table 1).

Table 1 The surface water quality in Jiaozhou bay in May, August and October

\begin{tabular}{|l|l|l|l|}
\hline & May & August & October \\
\hline $\begin{array}{l}\mathrm{Hg} \text { content in } \\
\text { seawater } / \mu \mathrm{gL}^{-1}\end{array}$ & $0.013-0.019$ & $0.021-0.025$ & $0.007-0.040$ \\
\hline $\begin{array}{l}\text { seawater standard } \\
\text { of China }\end{array}$ & first-class & first-class & first-class \\
\hline
\end{tabular}

\subsection{Horizontal Distribution of Bottom Layer}

In May, at the station 60 that located in the east coastal waters of Jiaozhou Bay, the concentration of $\mathrm{Hg}$ reached a relatively high level of $0.019 \mu \mathrm{g} / \mathrm{L}$, and a series of parallel lines with different gradients were formed. The $\mathrm{Hg}$ content decreased from $0.019 \mu \mathrm{g} / \mathrm{L}$ in the high concentration area near the east coast to $0.013 \mu \mathrm{g} / \mathrm{L}$ in the center of the bay.
In August,at station 60 and 53 that located in the east coastal waters of Jiaozhou Bay, the content of $\mathrm{Hg}$ reached a high level of $0.025 \mu \mathrm{g} / \mathrm{L}$, and a series of parallel lines with different gradients are formed. The $\mathrm{Hg}$ content decreased along gradients from $0.025 \mu \mathrm{g} / \mathrm{L}$ in the high content area near the east coast and the mouth of the bay to $0.021 \mu \mathrm{g} / \mathrm{L}$ in the center of the Bay (Fig. 2).

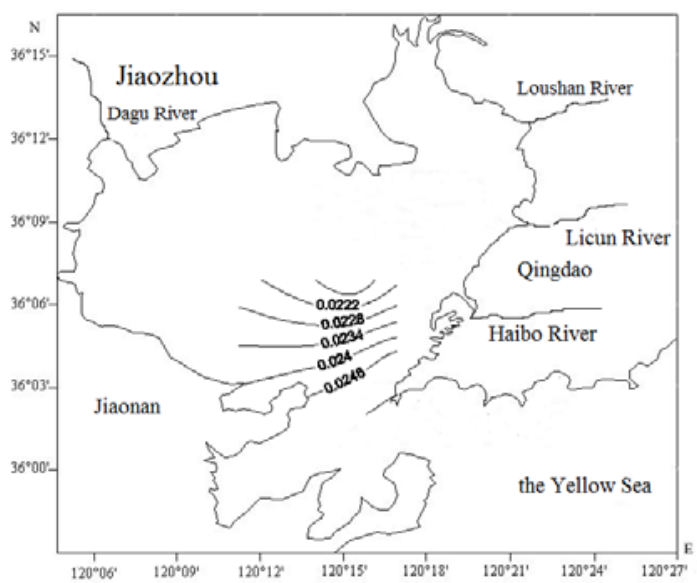

Fig.2 $\mathrm{Hg}$ content distribution at the bottom in Jiaozhou Bay in August $(\mu \mathrm{g} / \mathrm{L})$

In October, station 52 was in the south water area of Jiaozhou Bay mouth, the content of $\mathrm{Hg}$ reached a high level of $0.040 \mu \mathrm{g} / \mathrm{L}$. And a high content area of $\mathrm{Hg}$ was formed with the south water area of bay mouth as the center, forming a series of parallel lines with different gradients. The $\mathrm{Hg}$ content decreased along the gradients from $0.040 \mu \mathrm{g} / \mathrm{L}$ in the south of the bay mouth to 0.007 $\mu \mathrm{g} / \mathrm{L}$ in the center of the Bay (Fig. 3).

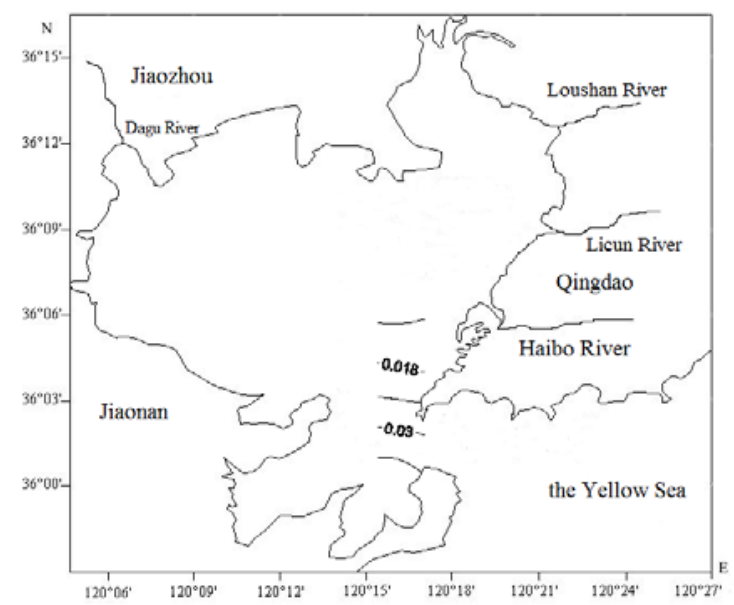

Fig.3 Hg content distribution at the bottom in Jiaozhou Bay in October $(\mu \mathrm{g} / \mathrm{L})$

\section{Discussion}

\subsection{Water Quality}

In Jiaozhou Bay, $\mathrm{Hg}$ content came from the surface runoff and atmospheric deposition. Hg firstly reached the surface of the water, and then, passed through the water from the 
surface to the bottom. Under the effect of vertical water [12-14], the Hg content in the bottom water of Jiaozhou Bay from the center of the bay to the south of the bay mouth varied from $0.007 \mu \mathrm{g} / \mathrm{L}$ to $0.040 \mu \mathrm{g} / \mathrm{L}$, which was in line with the national water quality standard for class I seawater. This showed that in terms of Hg content, in May, August and October, the water quality of Jiaozhou Bay from the center of the bay to the south of the bay mouth was not polluted by any $\mathrm{Hg}$ content.

In May, in the bottom of Jiaozhou Bay, the range of $\mathrm{Hg}$ content was $0.013-0.019 \mu \mathrm{g} / \mathrm{L}$, and the water of Jiaozhou Bay was not polluted by any $\mathrm{Hg}$ content. In the bottom of Jiaozhou Bay and the coastal water area in the East, the content of $\mathrm{Hg}$ reached a high level of $0.019 \mu \mathrm{g} / \mathrm{L}$, which was lower than $0.020 \mu \mathrm{g} / \mathrm{L}$. This showed that not only in the bottom of the east coast, but also in the bottomlayer of other waters of Jiaozhou Bay, the water was not polluted by any $\mathrm{Hg}$ content.

In August, in the bottom of Jiaozhou Bay, the range of $\mathrm{Hg}$ content of Jiaozhou Bay was 0.021-0.025 $\mu \mathrm{g} / \mathrm{L}$, and the water of Jiaozhou Bay was not polluted by any $\mathrm{Hg}$ content. In the bottom of Jiaozhou Bay, the east coastal area and the bay mouth water area, the content of $\mathrm{Hg}$ reached a high level of $0.025 \mu \mathrm{g} / \mathrm{L}$, and the content of $\mathrm{Hg}$ was far lower than $0.05 \mu \mathrm{g} / \mathrm{L}$. This showed that not only in the bottom of the east coast and bay mouth, but also in the bottom layer of other areas of Jiaozhou Bay, the water was not polluted by any $\mathrm{Hg}$ content.

In October, the content of $\mathrm{Hg}$ in the bottom of Jiaozhou Bay was between 0.007-0.040 $\mu \mathrm{g} / \mathrm{L}$. The water of Jiaozhou Bay was not polluted by $\mathrm{Hg}$ content. In the bottom of Jiaozhou Bay and the south water area of the bay mouth, the content of $\mathrm{Hg}$ reacheda relatively high level of $0.040 \mu \mathrm{g} / \mathrm{L}$, lower than $0.05 \mu \mathrm{g} / \mathrm{L}$. This showed that not only in the bottom of the bay mouth south, but also inthe bottom of other water areas of Jiaozhou Bay, the water was not polluted by any $\mathrm{Hg}$ content.

\subsection{Areas with Deposition}

In May, the range of $\mathrm{Hg}$ content was 0.013-0.019 $\mu \mathrm{g} / \mathrm{L}$ in the bottom of Jiaozhou Bay from the center of the bay to the south of the bay mouth. From the coastal waters in the east to the central waters of the Bay, the $\mathrm{Hg}$ content decreased along the gradients. It showed that in the coastal waters of the eastern part of the bay, there was a high deposition of the $\mathrm{Hg}$ content.

In August, the $\mathrm{Hg}$ content in the bottom water of Jiaozhou Bay, from the center of the bay to the south of the bay mouth ranged from $0.021 \mu \mathrm{g} / \mathrm{L}$ to $0.025 \mu \mathrm{g} / \mathrm{L}$. the $\mathrm{Hg}$ content decreased along the gradients from the east coastal waters and the bay mouth waters to the center of the bay. It was shown that there was a high deposition of $\mathrm{Hg}$ content in the east coastal waters and the bay mouth waters of the bay.

In October, in the bottom water of Jiaozhou Bay from the center of the bay to the south of the bay mouth, the $\mathrm{Hg}$ content ranged from 0.007 to $0.040 \mu \mathrm{g} / \mathrm{L}$. From the south water of the bay mouth to the central water of the Bay, the $\mathrm{Hg}$ content decreased along the gradients. It showed that there was a high deposition of $\mathrm{Hg}$ content in the south of the bay mouth.

Therefore, in May, August and October, in the bottom layer from the center of the bay to the south of the bay mouth in Jiaozhou Bay,there was a high deposition of $\mathrm{Hg}$ contentin the eastern part of the bay,the bay mouth watersandthe south of the bay mouth. From May to August, and then to October, there was a low deposition of $\mathrm{Hg}$ content in the central water area.

\section{Conclusion}

In Jiaozhou Bay, $\mathrm{Hg}$ content comes from the surface runoff and atmospheric deposition. $\mathrm{Hg}$ firstly came to the surface of the water, and then, passed through the water body from the surface to the bottom. In May, August and October, the range of $\mathrm{Hg}$ content in Jiaozhou Bay water body was $0.007-0.040 \mu \mathrm{g} / \mathrm{L}$, which was in line with the national water quality standard of class I sea water. This showed that in terms of $\mathrm{Hg}$ content, in May, August and October, the water of Jiaozhou Bay from the center of the bay to the south of the bay mouth was not polluted by any Hg content.

In the bottom of Jiaozhou Bay, in May, the range of $\mathrm{Hg}$ content in Jiaozhou Bay was 0.013-0.019 $\mu \mathrm{g} / \mathrm{L}$. In August, the content range of $\mathrm{Hg}$ in JiaozhouBay water was $0.021-0.025 \mu \mathrm{g} / \mathrm{L}$. In October, the range of $\mathrm{Hg}$ content in JiaozhouBay water was 0.007-0.040 $\mu \mathrm{g} / \mathrm{L}$. Therefore, in May, August and October, the water of Jiaozhou Bay was not polluted by any $\mathrm{Hg}$ contentin the eastern part of the bay, the bay mouth watersandthe south of the bay mouth

In May, August and October, in the bottom layer from the center of the bay to the south of the bay mouth in Jiaozhou Bay, there was a high deposition of $\mathrm{Hg}$ content. From May to August, and then to October, there was a low deposition of $\mathrm{Hg}$ content in the central water area.

\section{Acknowledgement}

This research was sponsored byResearch Projects of Guizhou Nationalities University ([2014]02), Research Projects of Guizhou Province Ministry of Education (KY [2014] 266), Research Projects of Guizhou Province Ministry of Science and Technology (LH [2014] 7376).

\section{References}

1. Chen $\mathrm{Yu}$, Gao Zhenhui, Qu Yanheng, Yang Dongfang and Tang Hongxia. Mercury distribution in the Jiaozhou Bay[J]. Chin. J. Oceanol. Limnol. 2007, 25(4): 455-458.

2. Dongfang Yang, Hairong Cao, Zhenhui Gao, Qing $\mathrm{Lu}$, Yanfeng Qu. Hg in Jiaozhou Bay I.Distribution and transition [J].Marine Environmental Science, 2008, 27 (1): 37-39.

3. Dongfang Yang, Leilei Wang, Zhenhui Gao, Lian Ju, Jiping Zeng. Hg in Jiaozhou Bay II. Distribution and pollution sources [J]. Marine Environmental Science, 2009, 28 (5): 501-505. 
4. Yu Chen, Yinjiang Zhang, Junhui Guo, Qiang Shi, Dongfang Yang. Distribution and Seasonal Variation of $\mathrm{Hg}$ (Heavy Metal) in the Waterbody of Jiaozhou Bay [J]. Ocean Development and Management, 2013, 30(6):81-83.

5. Dongfang Yang, Peiyan Sun, Chen Chen, Hongyan Bai, Qing Zhou. Pollution Source and Distribution of PHC in the Jiaozhou Bay Waters [J]. Coastal Engineering, 2013, 32(1): 60-72.

6. Dongfang Yang, Zijun Xu, Yanfeng Qu, Yanrong Zhou, Fei Teng. Distribution and Input Way of $\mathrm{Hg}$ in the Jiaozhou Bay [J]. Coastal Engineering, 2014, 33 (1): 67-78.

7. Yu Chen, Yanfeng Qu, Renlin Pei and Dongfang Yang. Effect of $\mathrm{Hg}$ in Jiaozhou Bay waters- The aquatic transfer process[J]. Advanced Materials Research Vols.955-959. 2014, 2491-2495.

8. Dongfang Yang, Sixi Zhu, Fengyou Wang, XiuqinYang and Yunjie Wu. Effect of $\mathrm{Hg}$ in Jiaozhou Bay waters- The land transfer process[J]. Advanced Materials Research Vols.955-959. 2014, 2496-2500.

9. Dongfang Yang, Sixi. Zhu, Fengyou Wang, Huazhoung $\mathrm{He}$ and Yunjie Wu. Effect of $\mathrm{Hg}$ in Jiaozhou Bay waters- The Temporal variation of the $\mathrm{Hg}$ content $[\mathrm{J}]$. Applied Mechanics and Materials Vols.556-562. 2014, 633-636.

10. Dongfang Yang, Fengyou Wang, Huazhong He, Youfu $\mathrm{Wu}$ and Sixi Zhu. Effect of $\mathrm{Hg}$ in Jiaozhou Bay waters- The change process of the Hg pollution sources[J]. Advanced Materials Research Vols.955959. 2014, 1443-1447.
11. Dongfang Yang, Xiao Geng, Yanfeng Qu, Hongyan Bai, Zijun Xu. Distribution and Gravity Characteristics of $\mathrm{Hg}$ (Heavy Metal) in the Waterbody of Jiaozhou Bay [J].Ocean Development and Management, 2014, 31 (12): 71-77.

12. Dongfang Yang, Fengyou Wang, Huozhong He, Sixi Zhu and Yunjie Wu. Vertical water body effect of benzene hexachloride[J]. Proceedings of the 2015 international symposium on computers and informatics. 2015, 2655-2660.

13. Dongfang Yang, Fengyou Wang, Xiaoli Zhao, Yunjie Wu, Sixi Zhu. Horizontal waterbody effect of hexachlorocyclohexane [J]. Sustainable Energy and Enviroment Protection. 2015, 191-195.

14. Dongfang Yang, Fengyou Wang, Xiuqin Yang, Yunjie Wu and Sixi Zhu. Water's effect of benzene hexachloride [J]. Advances in Computer Science Research. 2015, 2352: 198-204.

15. YANG D F, CHEN Y, GAO Z H, et al. Silicon Limitation on primary production and its destiny in Jiaozhou Bay, China IV transect offshore the coast with estuaries [J]. Chin. J. Oceanol. Limnol. 2005, 23(1): 72-90.

16. Dongfang Yang, Fan Wang, Zhenhui Gao, et al. Ecological Phenomena of Phytoplankton in Jiaozhou Bay [J]. Marine Science, 2004, 28 (6): 71-74.

17. State Oceanic Administration. The Specification for Marine Monitoring [Z]. Beijing: China Ocean Press, 1991. 